\title{
Practicing what we teach: Integrating osteopathic principles into practice
}

If those persons lamenting that our recent osteopathic medical school graduates are not incorporating their training in palpatory diagnosis and manipulative treatment into their practice are correct, some new approaches to teaching these essential elements of osteopathic medical practice should bode well. Before looking at the bold steps several of our osteopathic medical colleges now have taken to better integrate palpatory diagnosis and manipulative treatment into the clinical education, let us first review the reasons for the initial emergence of distinct departments of osteopathic principles and practice (sometimes called osteopathic sciences, or osteopathic medicine, departments) within our colleges.

The establishment of such departments was in response to a call to reverse the trend toward parity with allopathic medicine. This parity was occurring at the expense of osteopathic medicine's uniqueness. In our attempts to achieve equal educational status, osteopathic medical colleges developed or strengthened traditional medical school departments. Our colleges also employed increased numbers of fulltime faculty. However, volunteer faculty remained the primary teachers of osteopathic principles, particularly palpatory diagnosis and manipulative treatment. Because of competition for curriculum time and teaching facilities, departments with full-time faculty became dominant. Naturally, the creation of departments of osteopathic principles and practice with equal standing to other academic departments followed. Faculty in these departments had the primary responsibility of teaching palpatory diagnosis and manipulative treatment.

The American Association of Colleges of Osteopathic Medicine further assisted in the emergence of departments of osteopathic principles and practice: It formed the Educational Council on Osteopathic Principles, which developed a core curriculum. While the departments of osteopathic sciences increased in size, influence, and prestige, an interesting, albeit predictable, phenomenon occurred. Many faculty members who previously assumed the responsibility of teaching osteopathic techniques in the classroom, as well as practicing osteopathic prinicples in caring for their patients, delegated instruction to faculty members in the departments of osteopathic principles and practice. They also began relying more on referring their patients to the "experts" in manipulative treatment.

As a result, we have witnessed a clear territorial prerogative in that the teaching of palpatory diagnosis and manipulative treatment takes place almost exclusively during the students' preclinical training. Furthermore, faculty members whose practices are limited to manipulative medicine are the instructors. Osteopathic medical students are superbly educated in the basics of manipulative medicine, yet they seldom find their skills to be reinforced during clinical rotations in osteopathic medical hospitals and ambulatory clinics.

But the good news is that this territorial prerogative seems to be changing. Several osteopathic medical colleges have provided clinicians in various specialties with joint faculty appointments in the department of osteopathic principles and practice as well as in their own specialty department. These "new" faculty members in the department of osteopathic sciences are now teaching laboratory courses during the students' preclinical years. However, these instructors also review the curriculum and the students' clinical experiences in their primary department. Their responsibility is to assure that the full spectrum of os- 


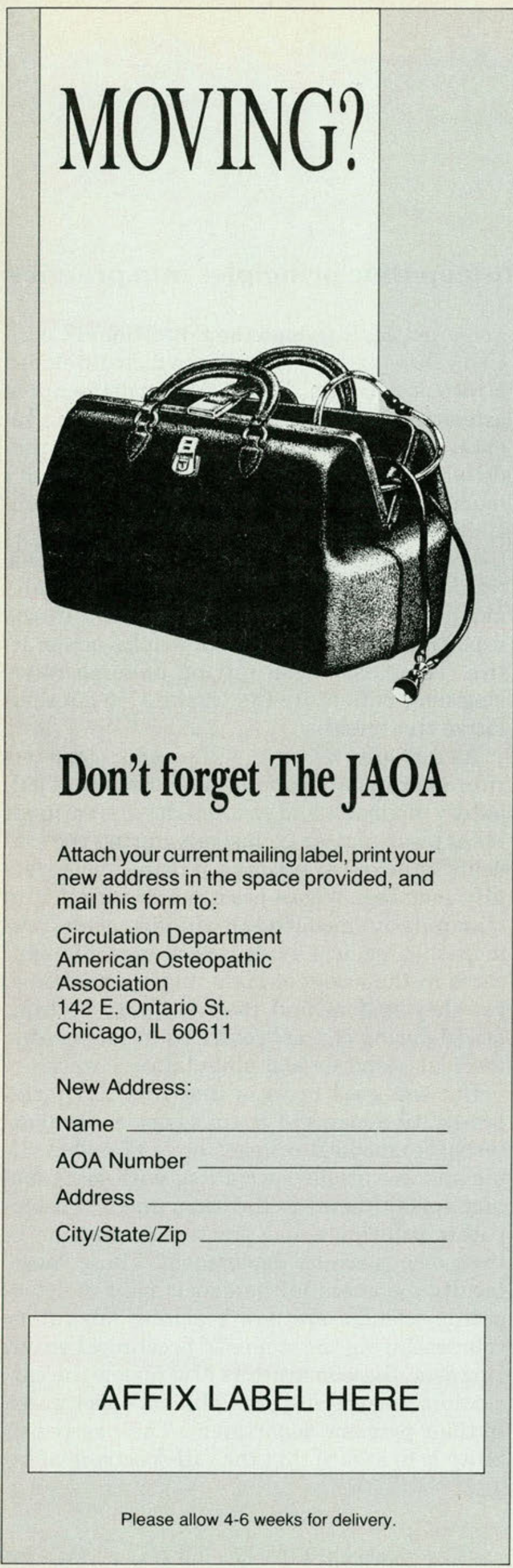

\section{editorial \\ (continued)}

teopathic principles and practice is included in the instructors' respective disciplines.

Just imagine the impact this approach will have on first- or second-year osteopathic medical students when they see the same internist, pediatrician, or surgeon who teaches in the clinical arena working side by side with the manipulative medicine specialist in teaching the basic skills of palpatory diagnosis and manipulative medicine.

Perhaps, as each department assumes its responsibility in teaching and incorporating osteopathic principles within its discipline, the actual presence of a department of osteopathic principles and practice in our schools of osteopathic medicine will be redundant. By pursuing such a goal, we have little to risk but much to gain.

THOMAS WESLEY ALLEN, DO Editor in Chief 


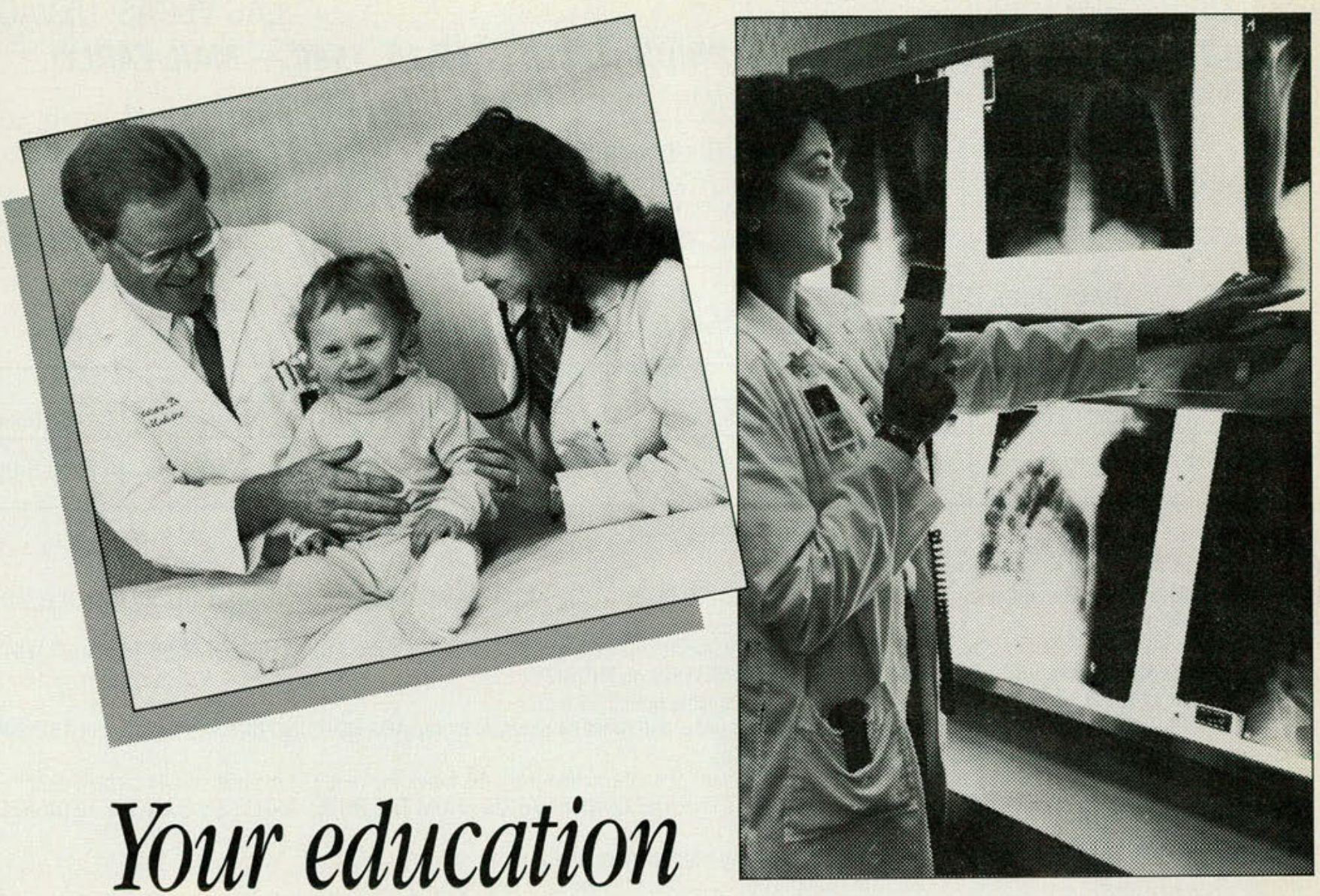

is important to us!

Left Pboto: Don Middleton, D.O. Resident, Tracy Overton, D.O., Resident and "small" patient at FOH. Right Pboto: Sucbeta Kulkarni, D.O., Intern

"Flint Osteopathic Hospital has provided acute and general health care for the Flint community for 50 years. The hospital is affiliated with Michigan State University and provides a full range of medical, surgical, emergency, and intensive care services. All medical and surgical subspecialties are covered. At FOH the intern and resident receives training in both outpatient ambulatory care as well as inpatient practices.

$\mathrm{FOH}$, with 359 beds, is the largest osteopathic hospital in Michigan offering intern and residency training programs for osteopathic physicians. The medical education program is designed to provide a structured curriculum and experience in diagnosis and treatment. Morning reports and guest physician lectures occur daily. Reading lists and objectives have been developed for each service. A monthly journal club is conducted by each clinical department. EKG conferences are scheduled twice monthly. The FOH Congdon Lecture Series brings both M.D. and D.O. physicians to the hospital each month. Prominent practitioners, representative of both medical communities, share expertise in research findings during these monthly, day-long seminar presentations.

Ambulatory clinics have been established and provide longitudinal continuity training for interns and residents. Both traditional and alternative track internships are available at $\mathrm{FOH}$. The hospital is a charter member of the Consortium of Osteopathic Graduate Medical Education and Training (COGMET) in association with Michigan State University."

\section{Residencies}

- Anesthesia

- Family Practice

- Gastroenterology

- Internal Medicine

- Obstetrics/Gynecology

- Ophthalmology

- Orthopedics

- Otorhinolaryngology

- Pathology

- Pulmonary

- Radiology

- Surgery

- Urology

\section{Fellowships/Subspecialty}

\section{Residencies}

- Medical Diseases of the Chest - Gastroenterology

One-year rotating internships Student externships

Christopber T. Meyer, D.O.

Vice President of Medical Education

Dennis V. DeStmone, D.O. Director of Medical Education

(313) $762-4707$

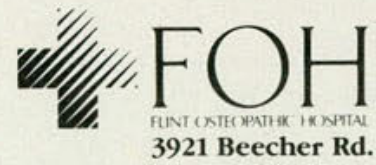

Flint, MI 48532

\section{Where family matters}




\section{AMERICAN OSTEOPATHIC ASSOCIATION HOTEL RESERVATION APPLICATION 95th Annual Convention and Scientific Seminar}

NOVEMBER 25-29, 1990

LAS VEGAS, NEVADA

\section{HOTELS REQUIRE RESERVATIONS PRIOR TO OCTOBER 15, 1990 - MAIL EARLY}

PLEASE INDICATE YOUR PREFERRED HOTEL (CHECK ONE) AND MAIL THIS FORM TO:

\begin{tabular}{c} 
AOA HOUSING BUREAU \\
$\%$ LAS VEGAS CONVENTION AND VISITORS AUTHORITY \\
3150 PARADISE ROAD \\
LAS VEGAS, NEVADA $89109-9096$ \\
\hline
\end{tabular}

\section{Las Vegas Hilton Hotel}

Las Vegas Hilton Hotel (HEADQUARTERS HOTEL)

\begin{tabular}{|c|c|c|c|c|}
\hline \multirow{2}{*}{ Single } & \multirow{2}{*}{$\begin{array}{c}\text { Double } \\
\text { or Twin }\end{array}$} & \multicolumn{3}{|c|}{ SUITES } \\
\cline { 3 - 5 } & Lanai (Petite) & One-Bedroom & Two-Bedroom \\
\hline$\$ 77$ & $\$ 77$ & $\$ 235$ & $\$ 285 \&$ Up & \$395 \& Up \\
\hline
\end{tabular}

Riviera Hotel

\begin{tabular}{|c|c|c|c|c|}
\hline \multirow{2}{*}{ Single } & Double & \multicolumn{3}{|c|}{ SUITES } \\
\cline { 3 - 5 } & or Twin & Petite & One-Bedroom & Two-Bedroom \\
\hline$\$ 69$ & $\$ 69$ & $\$ 125 \&$ Up & $\$ 175$ \& Up & $\$ 250$ \& Up \\
\hline
\end{tabular}

\section{Riviera Hotel}

(Above rates are subject to $7 \%$ Clark County Tax)

\section{IMPORTANT INFORMATION}

1. Please complete this form in detail and mail it to the AOA HOUSING BUREAU, $\%$ L LAS VEGAS CONVENTION AND VISITORS AUTHORITY, at the address shown above.

2. Do NOT send your reservations to the American Osteopathic Association's Central Office or to the hotel. MAIL THIS FORM DIRECTLY TO THE AOA HOUSING BUREAU, C/OLAS VEGAS CONVENTION AND VISITORS AUTHORITY.

3. Check out time is 12:00 Noon, therefore, rooms may not be available until 3:00 p.m.

4. All reservations will be processed on a first-come, first-served basis and must be received by the AOA HOUSING BUREAU by October 15, 1990 . You will receive a confirmation directly from the hotel.

5. The AOA Housing Bureau does NOT handle deposits. Upon receipt of confirmation from the hotel, the required deposit should be sent directly to the hotel. DO NOT SEND A DEPOSIT WITH THIS FORM - WAIT FOR THE CONFIRMATION FROM THE HOTEL AND THEN MAIL THE REQUIRED DEPOSIT DIRECTLY TO THE HOTEL.

6. Please complete this form in detail. Incomplete forms will delay room confirmation.

7. No Saturday arrivals are available. If the requested date is not available, the next date will be confirmed.

8. All changes in reservations must be made directly with the confirming hotel, and are subject to availability.

9. Registration, exhibits and didactic sessions will be held at the Las Vegas Convention Center. The major food functions will be held at the adjacent Las Vegas Hilton Hotel.

\section{Participating Groups Are:}

American Academy of Osteopathy

American College of General Practitioners in Osteopathic Medicine and Surgery

American College of Neuropsychiatrists

American College of Osteopathic Emergency Physicians

American Osteopathic Academy of Addictionology

American Osteopathic Academy of Sclerotherapy, Inc.

American Osteopathic College of Allergy and Immunology

American Osteopathic College of Dermatology
American Osteopathic College of Pathologists, Inc. American Osteopathic College of Preventive Medicine American Osteopathic College of Rehabilitation Medicine American Osteopathic College of Rheumatology, Inc. Academy of Osteopathic Directors of Medical Education Auxiliary to the American Osteopathic Association Research Conference

(The Association of Osteopathic State Executive Directors will also be meeting)

TYPE OF ACCOMMODATION: (please check one)

SINGLE $\square \quad$ DOUBLE $\square \quad$ TWIN $\square$

ARRIVAL DATE
SUITES: $\quad$ Lanai (Petite) $\square \quad 1$ Bedroom $\square \quad 2$ Bedroom DEPARTURE DATE

SEND CONFIRMATION TO: (Please Print)

NAME

ADDRESS

CITY 